\title{
Protection against Corrosion of Aluminum Alloy in Marine Environment by Lawsonia inermis
}

\author{
H. M. Hajar, ${ }^{1}$ F. Zulkifli, ${ }^{1}$ M. G. Mohd Sabri, ${ }^{2}$ and W. B. Wan Nik ${ }^{1}$ \\ ${ }^{1}$ School of Ocean Engineering, Universiti Malaysia Terengganu, 21030 Kuala Terengganu, Terengganu, Malaysia \\ ${ }^{2}$ School of Fundamental Science, Universiti Malaysia Terengganu, 21030 Kuala Terengganu, Terengganu, Malaysia \\ Correspondence should be addressed to W. B. Wan Nik; niksani@umt.edu.my
}

Received 6 June 2016; Revised 14 September 2016; Accepted 21 September 2016

Academic Editor: Michael J. Schütze

Copyright (c) 2016 H. M. Hajar et al. This is an open access article distributed under the Creative Commons Attribution License, which permits unrestricted use, distribution, and reproduction in any medium, provided the original work is properly cited.

\begin{abstract}
The corrosion performance of aluminum alloy 5083 (AA5083) was investigated in the splash zone area simulated in salt spray cabinet at ambient temperature. Three paint formulations were prepared in accordance with different percentages of henna extract. FTIR method was used to determine the constituent of henna while weight loss and electrochemical method were applied to investigate the inhibition behaviour. The findings show that corrosion rate of aluminum alloy decreased with the increases of henna extract in the coating formulation. The rise of charge transfer resistance $\left(R_{\mathrm{ct}}\right)$ value has contributed to the greater protection of the coated aluminum. The decrease in double layer capacitance value $\left(C_{\mathrm{dl}}\right)$ is another indicator that a better protective barrier has been formed in the presence of henna in the coating matrix.
\end{abstract}

\section{Introduction}

Aluminum was used widely in many sectors such as chemical plant, manufacturing lines, and marine industries. The advantage of using aluminum is due to their excellent corrosion resistance property and thus it becomes a priority in materials selections in most industries [1]. Aluminum alloy with 5000 series is excellent for the construction of small leisure boats, workboats, and the large high-speed passenger ship. The advantages of 5000 series aluminum are improved stability, reduced draft, minimized maintenance, and increased speed of the boats or ships. Unfortunately, aluminum suffers corrosion in the harsh environment such as seawater [2]. To overcome the problem, a few corrosion controls and prevention methods have been proposed. The method proposed includes material selection, coatings, corrosion inhibitors, cathodic protection, and also change in design [3]. Other than that, the mechanism of the corrosion protection consists of two mechanisms which are physical barrier effect and anodic protection. For physical barrier effect, the polymer coating acts as a barrier to the direct exposure of oxidants and aggressive anions. Meanwhile, the anodic protection system works when the conducting polymer with strong oxidative property acts as an oxidant to the test metals [4].

Interests in finding an effective corrosion inhibitor have become a major concern among researchers. Substance containing heteroatoms such as $\mathrm{O}, \mathrm{N}$, or $\mathrm{S}$ and multiple bonds was proven to be an excellent inhibitor. However, there are several factors contributing to a better inhibition efficiency such as the number and types of adsorbing groups as well as their molecular size, molecular structure, and mode of interaction with the corroding metal surface [5]. Henna, a herb which is widely used for dyeing purposes, has been studied because of its excellent inhibitive property and being relatively cheap and eco-friendly substance.

\section{Methods}

Henna extracts were obtained through rotary evaporation process and then used as corrosion inhibitor. Aluminum alloy 5083 was used as a substrate and the preparations of specimens (coupons) were referred to the American Society for Testing and Materials (ASTM) specifications. The coupons were coated with the paint incorporated with henna 


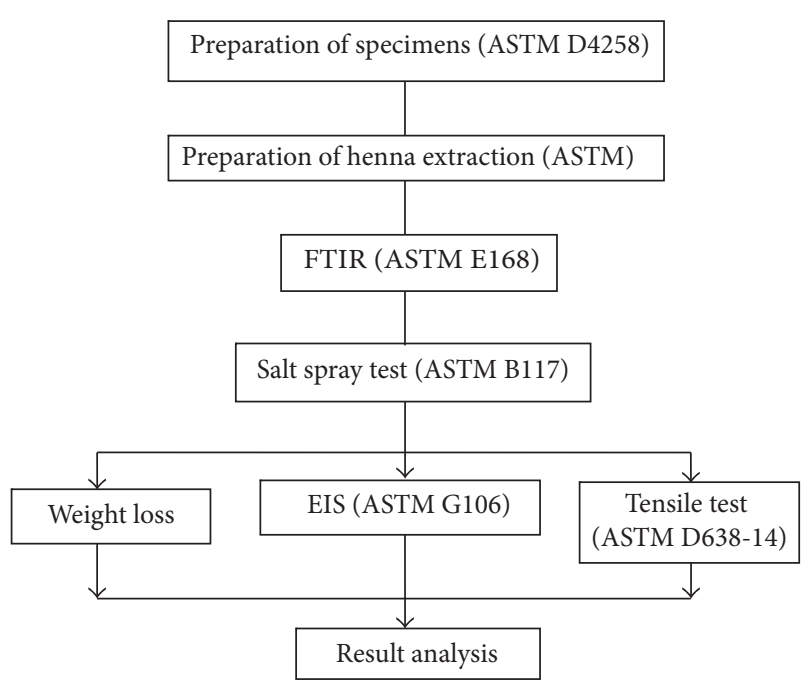

FIgURE 1: Methodological flow chart.

extract. The sample undergoes corrosion process in salt spray chamber where seawater was used as a corrosive medium. Figure 1 shows the flow of methodology in this study.

2.1. Sample Preparation. AA5083 was cut into square shape with the dimension of $25 \mathrm{~mm} \times 25 \mathrm{~mm} \times 3 \mathrm{~mm}$. It was polished by using 600, 800, and 1200 grit emery paper. The coupons were cleaned by using acetone and distilled water. The initial weights of specimens were recorded for each coupon and it was classified according to the characterization and period of exposure to seawater in salt spray chamber. This study investigated three different concentrations of henna extract which consist of $0 \%, 5 \%$ and $10 \%$ in coating matrix.

2.2. Extraction Preparation. Henna extraction has been used as corrosion inhibitor for aluminum alloy protection in this study. Dried henna leaves were crushed into powder. The henna powder was immersed in the ethanol solution and left for a week. After one week, the solutions were filtered. The remaining filtrates were collected and put into rotary evaporator (Rotavap) for extraction process.

2.3. Coating Preparation. The paint used in this experiment is alkyd paint. The paint was incorporated with henna extract until the mixture has become homogenous. A magnetic stirrer was used to mix the alkyd paint and henna extract. The percentage of henna extract in alkyd paint is tabulated in Table 1.

2.4. Salt Spray Test. Based on the industrial practices, salt spray cabinet is widely used to test components and coated panels for corrosion resistance [6]. In this research, salt spray cabinet Model DF/MP/450 had been used and was conducted according to ASTM B117.

The seawater used in salt spray test was obtained from Universiti Malaysia Terengganu hatchery. Seawater is an aggressive and complex electrolyte that affect nearly all
TABLE 1: Types of coating produced.

\begin{tabular}{lc}
\hline Paint & Henna extract (\%) \\
\hline Paint 1 (P1) & 0 \\
Paint 2 (P2) & 5 \\
Paint 3 (P3) & 10 \\
\hline
\end{tabular}

structural material to some extent and also seawater is the best media to be applied as a real environment to speed up the process of material corrosion.

2.5. Fourier Transform Infrared. The purpose of conducting Fourier Transform Infrared (FTIR) test is to expand the information of surface analysis and it is also used to characterize the coatings. Initially, Attenuated Total Reflectance (ATR) was used to examine the materials but abandoned after it only gave weak spectrum.

2.6. Weight Loss Measurement. In weight loss measurement, the coupons were cleaned using acetone and rinsed with distilled water. The coupons were weighed before they were left exposed in the salt spray chamber $\left(W_{i}\right)$.

Analytical balance was used as the weighing device with the sensitivity up to 4 decimal places in gram. The weight obtained after exposure is known as final weight $\left(W_{f}\right)$. Weight loss determination was carried out using the following equation.

Weight loss formula is as follows:

$$
W_{L}=W_{i}-W_{f}
$$

where $W_{L}$ is weight loss (mg), $W_{i}$ is initial weight $(\mathrm{mg})$, and $W_{f}$ is final weight (mg).

Weight loss (\%) formula is as follows:

$$
W_{L}(\%)=100-\left(1-\frac{W_{i}}{W_{f}}\right)
$$

where $W_{L}$ is weight loss (\%), $W_{i}$ is initial weight $(\mathrm{mg})$, and $W_{f}$ is final weight (mg).

Corrosion rate formula is as follows:

$$
\mathrm{CR}=87.6 \times \frac{W_{L}}{D A T}
$$

where CR is corrosion rate ( $\mathrm{mm} /$ year), $W_{L}$ is weight loss $(\mathrm{mg})$, $D$ is density of material $\left(\mathrm{g} / \mathrm{cm}^{3}\right), A$ is area of material $\left(\mathrm{cm}^{2}\right)$, and $T$ is time (hour).

2.7. Tensile Test. Tensile test was carried out by hydraulically operated tensile testing machine with the maximum capacity of $50 \mathrm{kN}$ under static load condition. The load is uniaxially applied on the specimen at a crosshead speed of $5 \mathrm{~mm} / \mathrm{min}$. The data was collected using a computer control software package. 
<smiles>O=C1C=C(O)C(=O)c2ccccc21</smiles>

Figure 2: Lawsone molecular structure.

\section{Results and Discussion}

The data were collected through several methods including FTIR spectroscopy, weight loss measurement, Electrochemical Impedance Spectroscopy (EIS), and tensile test. All data were analyzed and represented in the form of graph and tables.

3.1. Fourier Transform Infrared. Figure 2 shows the molecular structure of lawsone which is the main component in henna. Three major functional groups which can be derived from the structure are phenols $\mathrm{O}-\mathrm{H}$ and $\mathrm{C}=\mathrm{O}$ and alkenes $\mathrm{C}=\mathrm{C}$ [7]. They are also known as flavanoids which consists of carbonyl group ( $\mathrm{C}=\mathrm{O}$, Ketone), $\mathrm{O}-\mathrm{H}$ group, and aromatic group [8].

Figure 3 shows the IR spectrum of henna. The phenolic group $(\mathrm{O}-\mathrm{H})$ stretch appeared at $3299 \mathrm{~cm}^{-1}$. The aromatic $\mathrm{C}=\mathrm{C}$ stretching frequency appeared at $1735.2 \mathrm{~cm}^{-1}$ while the $\mathrm{C}=\mathrm{O}$ stretching frequency appeared at $1625.1 \mathrm{~cm}^{-1}$. The IUPAC name of henna is 2-hydroxy-1,4-naphthoquinone [9]. The phenol group of lawsone would donate electron to the metal to achieve its noble state or orbit, whereas the metal would receive the electron to become more stable. This occurrence causes the indirect retardation of further redox reaction and could resist corrosion from acting [10].

3.2. Weight Loss Measurement. Figure 4 shows the weight losses of the coated samples in the absence and presence of henna as inhibitor. The formulation of $10 \%$ of henna extract (P3) coating shows the most stable performance followed by $5 \%$ of henna extract (P2) coating. The presence of phenol group in lawsone structure helps the metal become more stable via the electron donation of phenol group [11] and also it was able to give more protection to the surface of aluminum alloy AA5083 which is exposed to oxygen [12].

Figure 4 also shows that $10 \%$ of henna extract coating has the lowest amount of weight loss. This is because the henna extract contained in the coating used is in the highest percentage. Not only do the coatings ensure the adhesion between metal substrate and organic coatings, but also they are providing a thin barrier with the efficient effect against oxygen diffusion on metal interface. The highest percentage of henna extract had caused the decrease in weight loss due to the inhibitive effect of lawsone by the formation of insoluble complex compounds combined with the metal cations [13].

Figure 5 shows the result of corrosion rates calculated from the weight losses data. The graph shows that the value of corrosion rate for coating incorporated with henna extract is lower than bare metal. As the concentration of henna in
TABLE 2: Electrochemical parameters of coated sample in the presence and absence of henna extract.

\begin{tabular}{lrc}
\hline Henna extract $(\%)$ & $R_{\mathrm{ct}}\left(\mathrm{k} \Omega \mathrm{cm}^{-2}\right)$ & $C_{\mathrm{dl}}\left(\mu \mathrm{F} \mathrm{cm}^{-2}\right)$ \\
\hline 0 & 0.567820 & 0.018342 \\
5 & 1.346021 & 0.001354 \\
10 & 1.890300 & 0.000034 \\
\hline
\end{tabular}

the coating matrix increases, the corrosion rate was found to decrease. The coated samples without any inhibitor coating show a slight increase of corrosion rate. Upon incorporation of henna, the inhibitive action of Lawsonia extract could be due to the adsorption of its molecules on the substrate surface making a barrier in order to protect its surface [9].

3.3. Electrochemical Impedance Spectroscopy (EIS). Table 2 shows the values of charge transfer resistance and double layer capacitance of AA5083. The data shows that coated samples incorporated with henna have produced higher charge transfer resistance $\left(R_{\mathrm{ct}}\right)$ compared to bare metal. The highest resistance obtained in this research is the coated sample with $10 \%$ of henna extract coating.

Figure 6 shows the Nyquist plot of AA5083 with and without coating. It can be seen that the coated coupon with $0 \%$ henna extract exhibits the smallest semicircle, followed by a coated coupon incorporated with $5 \%$ of henna extract. The largest semicircle is represented by $10 \%$ henna extract. The size of the semicircle contributes to the degree of corrosion resistance. The larger semicircle indicates a better degree of resistance. Increasing value of $R_{\mathrm{ct}}$ with the addition of henna extract percentage gave a better performance to retard corrosion due to the formation of oxide layer [8].

A high antioxidant property of henna has contributed to the increment of electrical resistance on the aluminum surface [14]. It indicates that when a percentage of henna extracts increase, the corrosion resistance also increases and the corrosion rate decreases. Furthermore, the high impedance value of the coating is related to the formation of the deposited layer and consequently slows down the rate of electrolyte penetration into the coating [15].

3.4. Tensile Strength. Figure 7 shows the plot of stress and strain curve. The coupons show a linearity at the beginning until reaching the ultimate stress around $175 \mathrm{MPa}$. Then, the stress value decreases until it goes into necking phase and rupture.

Ultimate strength or tensile strength is obtained by dividing maximum load by original area of cross section of coupon.

The tensile stress is achieved where the decrease in the cross-sectional area is greater than the increase in deformation load which is caused by strain hardening. In this region, plastic deformation was concerned. The stress begin to decrease. Coupon begins to neck down rapidly when the cross-sectional area decreases far more rapidly than the load increasing by strain hardening [16]. The actual load required 


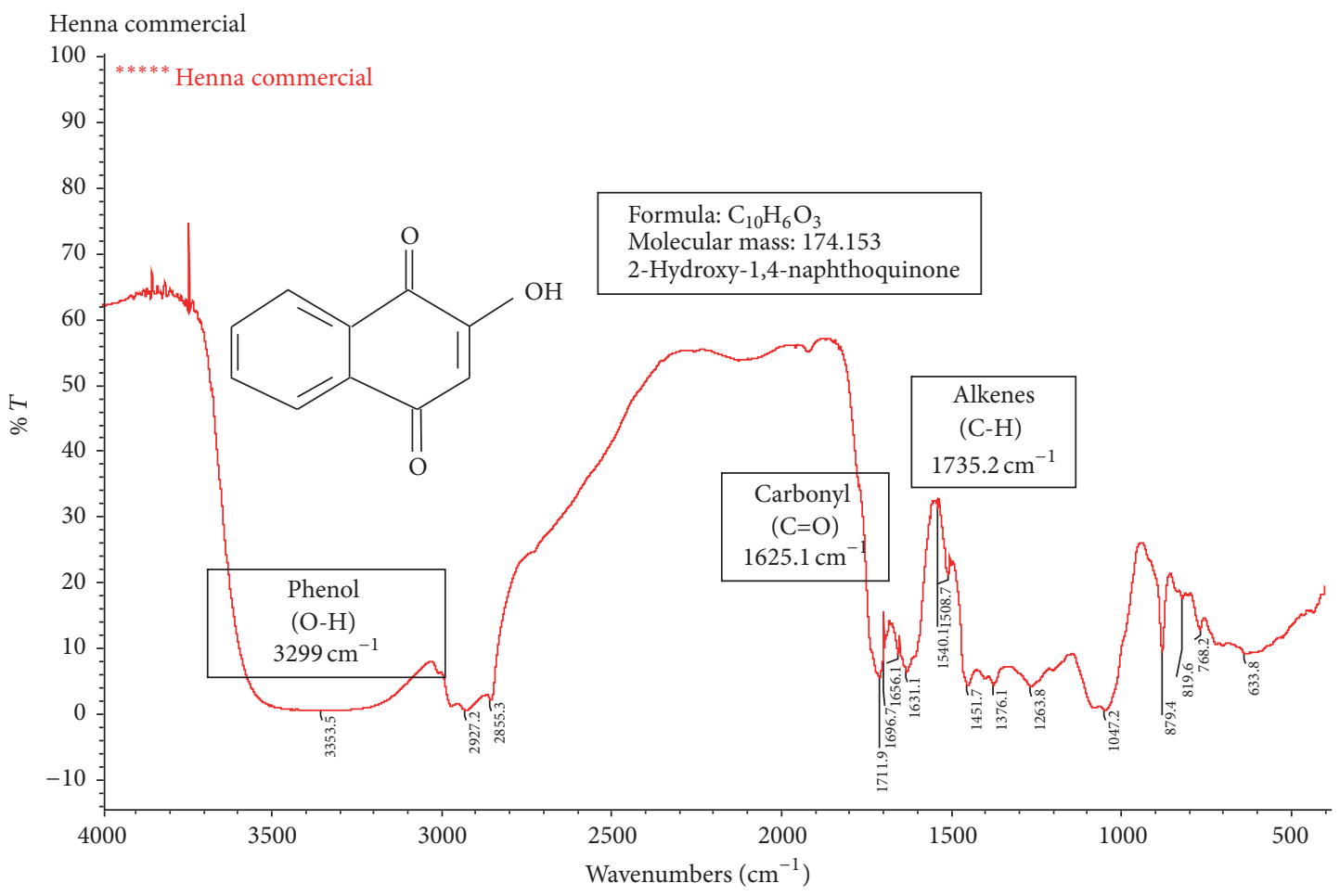

FIGURE 3: IR spectra for henna extraction using FTIR.

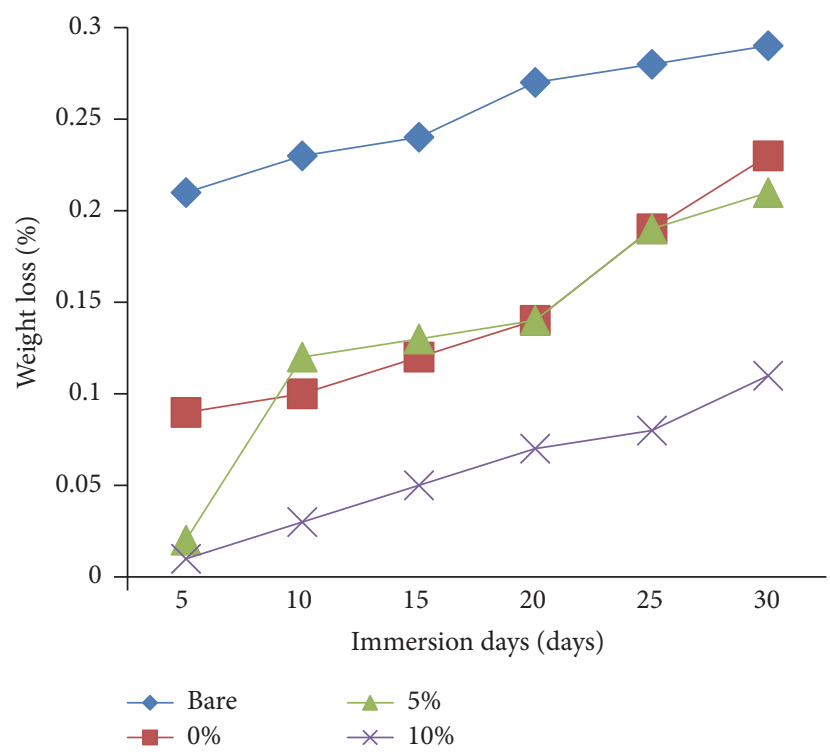

FIGURE 4: Result of weight loss of coupons.

to deform the coupon falls off and stress continues to decrease until fracture occurs.

\section{Conclusions}

The henna extract acts as an excellent inhibitor in way of protective coating method. The highest percentage of henna extract provides the highest resistant layer and makes the

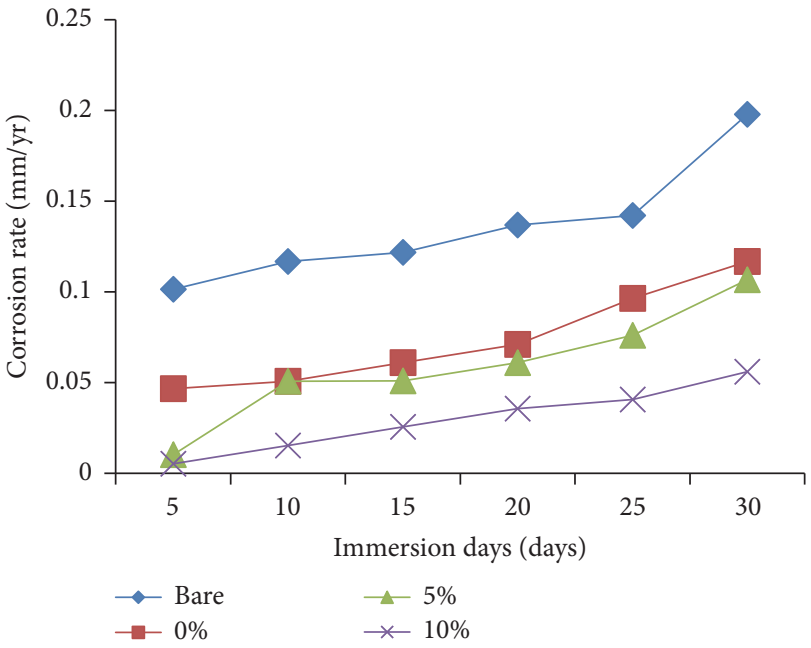

FIgURE 5: Corrosion rate of coupons until day 30.

coupon less corroded. Paint 3 with $10 \%$ of henna extract gives the lowest value of corrosion rate which is $0.0296 \mathrm{~mm} /$ year compared to bare metal, paint 1 , and paint 2 .

The stress-strain curve shows a linearity in the beginning until stress exceeds about $175 \mathrm{MPa}$. The stress keeps decreasing until, at a certain point, it goes into necking phase and rupture.

\section{Competing Interests}

The authors declare that they have no competing interests. 


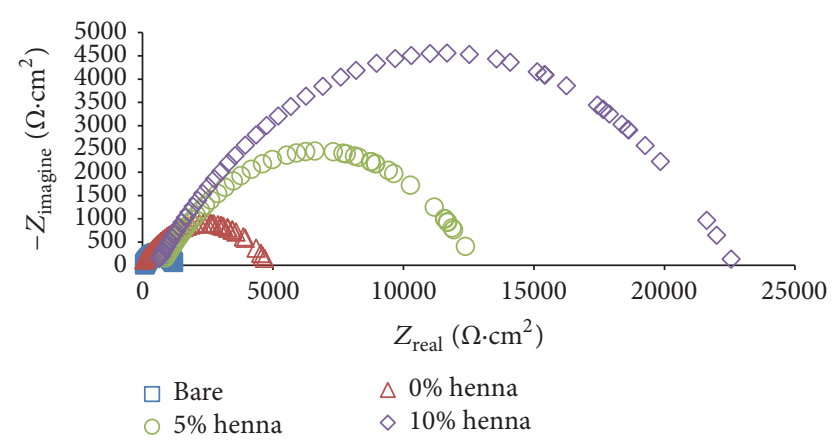

Figure 6: Nyquist plot of bare and coated samples.

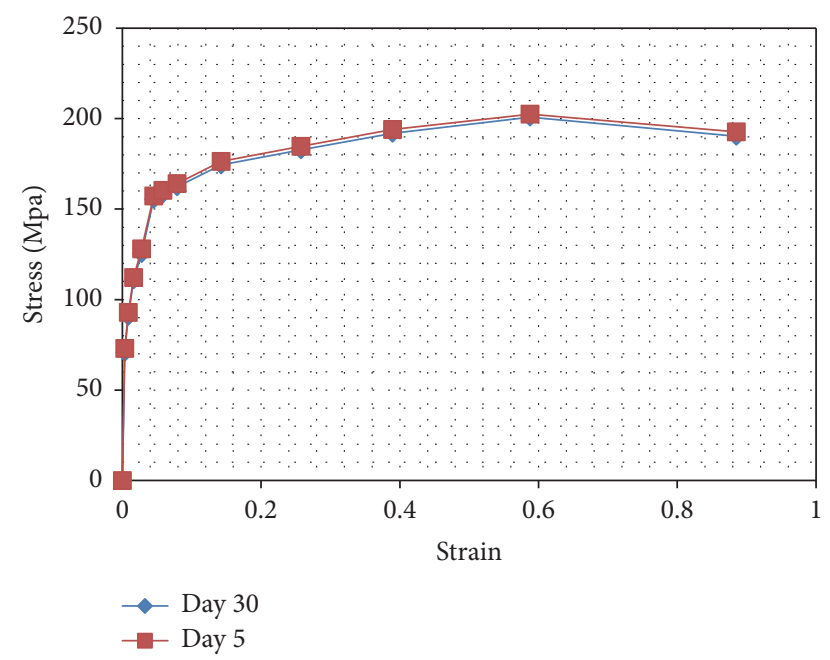

FIGURE 7: Stress and strain curve of a coated aluminum alloy.

\section{Acknowledgments}

The authors greatly acknowledge the Research Fund Look East Policy 2.0, Vot. no. 53168 and also Miss. Nadia Zahamudin and Mr. Tan Wu Huei for their direct contribution in this study.

\section{References}

[1] S.-J. Kim and S.-K. Jang, "Effects of solution heat treatment on corrosion resistance of 5083F Al alloy," Transactions of Nonferrous Metals Society of China, vol. 19, no. 4, pp. 887-891, 2009.

[2] Z. Ahmad and B. J. Abdul Aleem, "Degradation of aluminum metal matrix composites in salt water and its control," Materials and Design, vol. 23, no. 2, pp. 173-180, 2002.

[3] ASM International, "The effects and economic impact of corrosion," in Corrosion: Understanding the Basics, pp. 1-20, ASM International, 2000.

[4] T. Ohtsuka, "Corrosion protection of steels by conducting polymer coating," International Journal of Corrosion, vol. 2012, Article ID 915090, 7 pages, 2012.

[5] A. Nahlé, I. Abu-Abdoun, I. Abdel-Rahman, and M. Al-Khayat, "UAE neem extract as a corrosion inhibitor for carbon steel in $\mathrm{HCl}$ solution," International Journal of Corrosion, vol. 2010, Article ID 460154, 9 pages, 2010.
[6] M. Belkhaouda, L. Bazzi, R. Salghi et al., "Effect of the heat treatment on the behaviour of the corrosion and passivation of 3003 aluminium alloy in synthetic solution," Journal of Materials and Environmental Science, vol. 1, no. 1, pp. 25-33, 2010.

[7] K. S. Singh, Y. V. Singh, and M. Singh, "Agro-history, uses and distribution of henna (Lawsoniainermis L. Syn. Alba Lam)," in Henna: Cultivation, Improvement and Trade Jodhpur, Central Arid Zone Research Institute, 2005.

[8] F. Gapsari, R. Soenoko, A. Suprapto, and W. Suprapto, "Bee wax propolis extract as eco-friendly corrosion inhibitors for 304SS in sulfuric acid," International Journal of Corrosion, vol. 2015, Article ID 567202, 10 pages, 2015.

[9] A. Y. El-Etre, M. Abdallah, and Z. E. El-Tantawy, "Corrosion inhibition of some metals using lawsonia extract," Corrosion Science, vol. 47, no. 2, pp. 385-395, 2005.

[10] W. B. Wan Nik, F. Zulkifli, R. Rosliza, and M. M. Rahman, "Lawsonia Inermis as green inhibitor for corrosion protection of aluminium alloy," International Journal of Modern Engineering and Research Technology, vol. 1, pp. 723-728, 2011.

[11] A. Hamdy and N. S. El-Gendy, "Thermodynamic, adsorption and electrochemical studies for corrosion inhibition of carbon steel by henna extract in acid medium," Egyptian Journal of Petroleum, vol. 22, no. 1, pp. 17-25, 2013.

[12] A. Yağan, N. Ö. Pekmez, and A. Yildiz, "Corrosion inhibition by poly(N-ethylaniline) coatings of mild steel in aqueous acidic solutions," Progress in Organic Coatings, vol. 57, no. 4, pp. 314318, 2006.

[13] A. Motalebi, M. Nasr-Esfahani, R. Ali, and M. Pourriahi, "Improvement of corrosion performance of $316 \mathrm{~L}$ stainless steel via PVTMS/henna thin film," Progress in Natural Science: Materials International, vol. 22, no. 5, pp. 392-400, 2012.

[14] E. Akbarinezhad, F. Rezaei, and J. Neshati, "Evaluation of a high resistance paint coating with EIS measurements: effect of high AC perturbations," Progress in Organic Coatings, vol. 61, no. 1, pp. 45-52, 2008.

[15] A. Al-Borno, X. Chen, and S. K. Dhoke, "Effect of high temperature sodium hydroxide immersion on fusion bond epoxy coating," International Journal of Corrosion, vol. 2015, Article ID 903478, 7 pages, 2015.

[16] S. J. Kim and J. Y. Ko, "Investigation on optimum protection potential of high-strength $\mathrm{Al}$ alloy (5456-H116) for application in ships," Journal of the Korean Society of Marine Engineering, vol. 30, no. 1, pp. 157-168, 2006. 

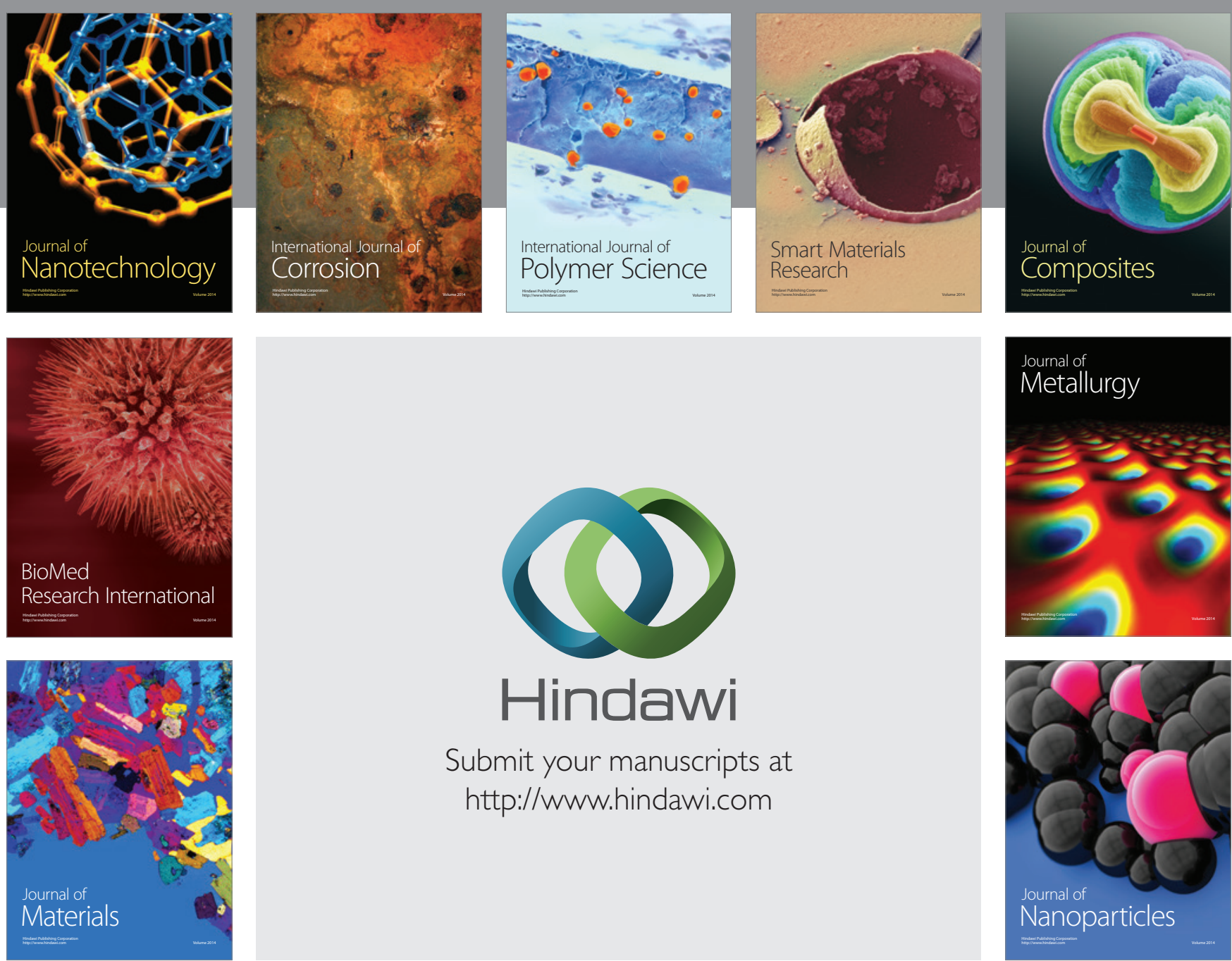

\section{Hindawi}

Submit your manuscripts at

http://www.hindawi.com

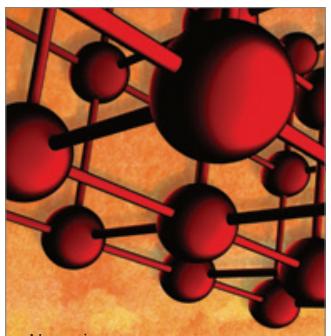

Materials Science and Engineering
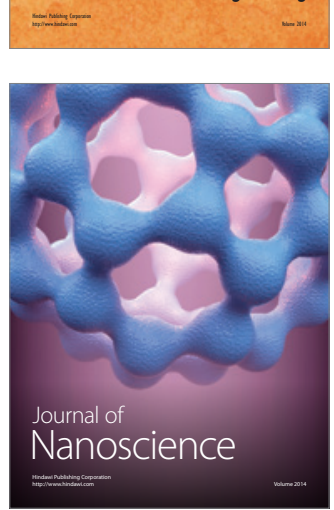
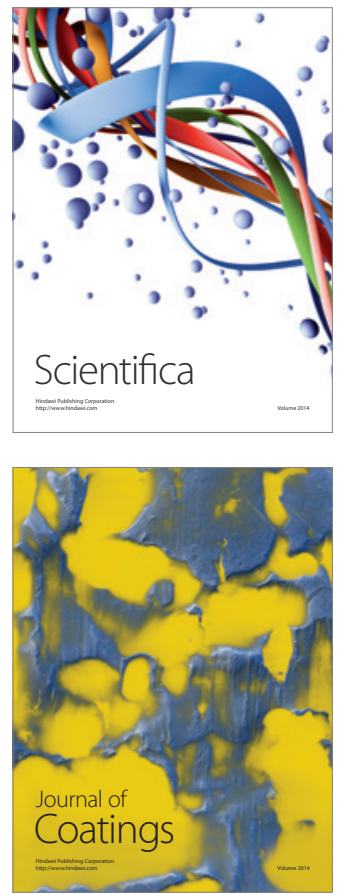
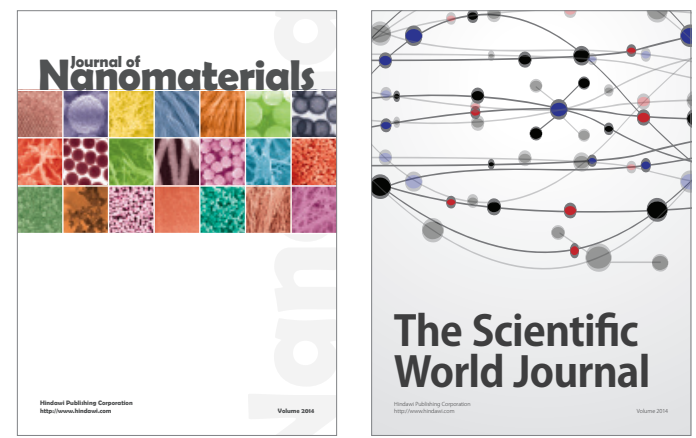

The Scientific World Journal
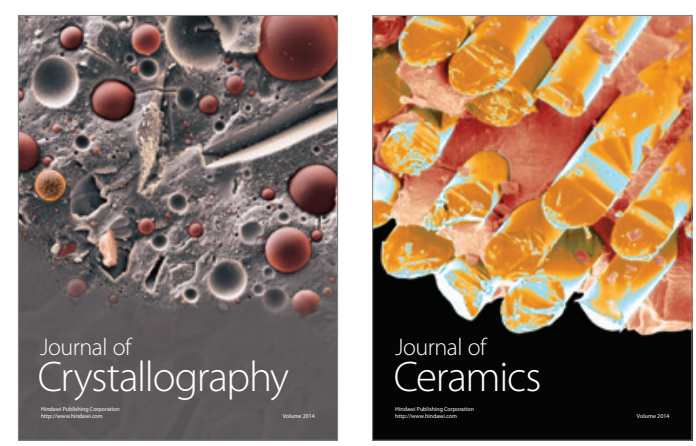
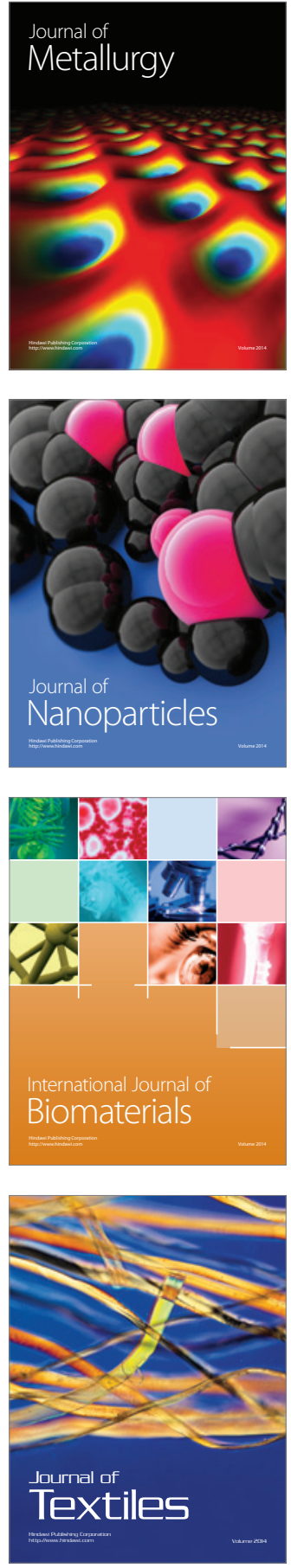